\title{
Changes and Future Challenges in the Social Work Profession in Israel Based on Stories of Veteran Social Workers
}

\author{
Zaher Accariya \\ Sakhnin College, Sakhnin, Israel \\ Email: accariya@gmail.com
}

Received 27 May 2016; accepted 1 August 2016; published 4 August 2016

Copyright (C) 2016 by author and Scientific Research Publishing Inc.

This work is licensed under the Creative Commons Attribution International License (CC BY). http://creativecommons.org/licenses/by/4.0/

(c) (i) Open Access

\section{Abstract}

The purpose of this study is to identify: the fluctuations and the changes in the social work profession in Israel reflected in the perceptions of veteran social workers, the origins of the profession in Israel, and the changes in the role of the social worker from its inception in Israel until today. This study used a qualitative research method. Interviews were conducted by students studying for their master of social work degree in the school of social work and social welfare at the Hebrew University of Jerusalem in a course on the historical and philosophical origins of the social work. the findings highlight the differences in the veteran social workers' perceptions of the definition, nature, and role of social work in the country that parallel major developments of the profession in the country from its first days until the present, as reflected in the different periods of growth, expansion and development of the state of Israel.

\section{Keywords}

Veteran Social Worker, Profession, Perception, Social Work Profession

\section{Background Research}

\subsection{Development of Social Work Profession}

Much of what is written about social work grew out of professional and academic thinking. But Payne (Payne, 2005) indicates social workers contribute to how social work structured by social construction. Little written about how social workers themselves define and describe the social work.

In the United States and other countries the purpose of social work involved in helping underprivileged populations by helping individual adaptation and improvement of social conditions through social action and 
social change. The emphasis was placed on the overall practice of social work. This practice involves working with systems of patients at all levels: link patients to resources exist, betting organizations to promote the responsiveness of systems resources, support social policy right to ensure equitable distribution of resources, and other aspects from the practice of social work (Han \& Chow, 2011).

Jewish communities and community boards of mixed cities were set up Chambers of Social Work, and the practice which was inclusive: included financial assistance, child protection, counseling and other services to families. Over time a certain amount of expertise. Some of the social workers working with the needy, others engaged in preventing children in school and few of them are focused on the needs of unique populations.

The first professional social workers and social classes were refugees from Germany after the Nazis came to government. The first course for social workers opened in Jerusalem in 1934, and was directed by Sidi Vronsky.

The beginning of professional social work in Israel was in 1931, which established the National Council, an institution of self-government of the Jewish community under the British mandate, the Department of Social Work.

First, there was no internal differentiation in social services and social work was almost exclusively local offices of Social Work. Only a few employees were in other settings such as hospitals, test services, services for immigrants and schools.

With time social work entered new areas such as military mental health services, employment and other welfare. Diversity has brought changes in the patterns of vocational training and the organization of the profession (Shapiro et al., 1998).

Until the fifties, the eligibility for grants management and major components were the work of social workers. After the enactment of Social Security and gradual process that lasted thirty years, Chambers released Relief Support programs for the needy, and social workers stopped from dealing with the middle class.

In recent decades, the Knesset enacted a series of laws imposing social workers to intervene in risk situations (Youth Law-care and supervision, the Prevention of Domestic Violence; and the amendment of the Penal Codeprotecting the helpless). Alongside long-term care insurance law exists that requires the employees of the social services departments to coordinate the work of the committees needy examine and eligibility for nursing services and determine a treatment plan entitlement (Shnit, 1998).

Academization process of the social work began in 1958 with the opening of the School of Social Work and Social Welfare. The decision then it was at the time of the determination of the basic training and practice in social work will be through undergraduate studies (Neipris, 1992).

In the early seventies, Open University degree pathways in social work. Today, all universities have doctoral programs, aimed mainly at research and academic teaching staff training (Shapiro et al., 1998).

Another change relates to the increase in the volume of domestic research. The present study contemporary social work manages to cover a wide range of topics (Shapiro et al., 2002).

\subsection{Targeting Social Work Profession in Israel}

The early days of social work in Israel is influenced by European and American approaches to the treatment, the first focusing on social reform and settlement, while the second deals with more of an individual and his family (Konrad, 1993; Neipris, 1992).

In the 40th and 50th social workers in the Israel described themselves as therapists, and psychiatrists, and work with their patients conducted primarily through the use of the concepts of psychoanalytic theory and practice. 60s were characterized by a change in the perception of social work in Israel. During this period the focus of practitioners focused primarily on community organizing, policy design and social activities (Shapiro et al, 1998; Shapiro et al, 1992).

In the 70th focus was creating a social worker capabilities and expertise in the treatment of individuals, families, groups and communities and be able to drive broader social change processes, and be able to make proper use of community resources and versatile. In the 80's was very obvious that the use of new psychological theories such as self psychology, ecological approach, object-relational approach, theories of marital and family therapy, cognitive and behavioral approaches, crisis intervention and empowerment approach.

In the 90th social work profession in the country has faced many challenges in the areas of specialization, research and professional knowledge base construction.

While social workers of the new millennium have invested most of their efforts in the development of thera- 
peutic practice models, today's social workers have become more willing to work even programs that require them courses of action considered less professional. They are also willing to compromise on benefits and work conditions part of the work to survive (Shapiro et al., 1998; Shapiro et al., 1992).

\section{The Research Method}

The methodology chosen to stand at the base of this study is the methodology Qualitative-narrative (life stories). This theoretically oriented approach and methodology that examines the nature and legality of one's life narrative (Bruner, 1986; Sarbin, 1986). Under this approach, the same is the story people tell themselves and others about themselves. This story is told in the context of historical, cultural and social (Riessman \& Quinney, 2005).

This study analyzed the social work profession in Israel based on the narratives of a fifteen social workers who have accompanied its development throughout their long years of involvement. This study triangulated their narratives with a survey of professional literature pertaining to this subject.

\section{The Research Process}

In order to meet the objectives of the study, the researcher used a qualitative research method. Interviews were conducted by students studying for their master of social work degree in the school of social work and social welfare at the Hebrew University of Jerusalem in a course on the historical and philosophical origins of the social work. The students were provided with an interview guide, which supplied them with a prepared list of questions.

The interviewees were divided into three age groups: active social workers who had been working up to thirty years in the profession, middle-aged social workers who had just entered the profession and still do not have enough experience in the profession. In other words, In other words, the participants are new to the profession of social work. They do not have ten years of profession and retired social workers who have left the profession after more than thirty years in the profession.

Interviews were chosen that illustrated different periods, giving diverse perspectives of the profession. The fifteen most richly detailed narratives were chosen for analysis.

\section{Results}

The interviews revealed a long list of changes regarding the profession itself, the status of the social worker, and the identity and range of the social worker's responsibilities. A non-academic profession in its early days in the country, today anyone wishing to practice social work may acquire education in the subject at one of the universities or colleges in Israel or around the world with a faculty of social work. Practitioners must have, at the very least, a bachelor's degree in social work. Over the years, the profession has acquired prestige, and many people seek to study it. The findings of this study show that the changes in the profession and the role of the social worker in this country are linked, among other things, to social and political factors, and to the economic policies that characterized each period in the history of the profession. Over the years, social work in Israel has expanded into various areas of specialization in organizations, community, and direct care.

This study presents a comprehensive overview of the social work profession in Israel, especially with respect to its practice, that is particularly important for anyone interested in choosing a career in this profession. It shows that social workers chose this profession out of fondness for this line of work and tend to encourage others to choose this career not only because they feel that it is a satisfying one, but also because increasing the number of social workers works for the good of the community.

The study shows that one reason for the changes and adjustments that the profession underwent was the persistent gap between the vision of its founders and developers, who came from Western countries and who had their own specific cultural values and goals, and the local cultural perceptions existing in the country. These changes did not always suit the goals and objectives for which the profession was developed.

The present study presents the two significant aspects of social work: theoretical and practical. It emphasizes changes that have occurred in the character of a profession that initially came to address the needs of a downtrodden population but has changed over time to one whose primary aims are specialized clinical professionalism and connecting service-providing professionals with those members of a weaker population who require those services. In addition, the study shows that veteran social workers consider social work to be a profession 
that involves adapting a person to his surroundings and vice versa.

However, the study emphasizes that local social service departments are no longer involved in providing financial assistance, except in emergencies. Instead, they focus on consultation, social care, and community program development. This change has increased the professional nature of social work.

The findings reveal that the stature of social work is dependent on a number of important factors, among them the professional development of the individuals involved in it; community resources; policy, governance and politics; and the general socio-professional environment. Some interviewees went so far as to link the status of the profession, its image in the populace's eyes, and the self-image of those involved in it to several factors: the legal status of the profession in the country; the amount of control it had over its own areas of activities; the position of the social workers themselves in the bureaucratic systems; and the makeup of the profession in terms of social workers' gender, education, and income.

The retired veteran social workers also mentioned the subject of professional qualification. The first program to qualify professionally-trained social workers was based on the three-year American model, as opposed to the preceding one that took only two years and that did not award an academic degree.

Regarding attitudes of the general public and policy makers, the study found that this area in particular did not undergo significant change. The majority claimed that the profession is not well respected, and that the public are all too often aware of mistakes or wrong-doings caused by social workers.

Another prominent finding from the narratives concerns differences that have occurred in the relationships between the social workers and their clients, in which the concept of who holds power and control has changed from the social worker to the client: clients are not as passive as they once used to be and are now full partners in decisions regarding their treatment and provision of needs.

An additional finding shows that developments in the education of social workers have led to an increase in the scope of local research. According to the veteran social workers, the theories that guide practical work in Israel are still the original ones, yet additional research work provides a solid, empirical basis for local fieldwork. The majority of the study's participants believe that objective, systematic research is important and necessary for the advance of the profession, although it is no less important than reflective thinking, according to which professional social workers must exhibit self-accountability regarding their work, and be ready to accept constructive criticism from those around them.

One thing that significantly influenced the veteran social workers' perceptions is the increased number of committee briefs, and a greater focus on paperwork and reports than in the past.

\section{Discussion}

The social work profession in Israel has undergone a sequence of developmental stages, during which it has been influenced by numerous factors and processes, countless decisions by policy makers in the country, and many changes in all facets of life. All of these have led to the present structure of this vocation and the design of its professional status and identity. This study focuses on the various stages of development that the social work profession has gone and continues to go through in this country, from its initial inception and up to its transformation into a profession with a distinct identity. In other words, it surveys the profession's development process from pre-State days until today. In addition, this study offers a number of definitions regarding the role of the social worker in Israel.

The purpose of the research is to study the social work profession in Israel-its definition, status, identity and roles-from the time it was first recognized as such in the country till today, and to answer the following questions: How are the fluctuations and changes in the social work profession in Israel reflected in the perceptions of veteran social workers? What are the origins of the profession in Israel? Has there been a change in the role of the social worker from its inception in Israel until today? What are the roles of the social worker? How does this profession differ from other health care professions? What are areas of care are covered by the profession? How is the profession perceived by those who work in it and by other community stakeholders? What factors have influenced the professions from its inception until today? Is there a connection between the academic changes that have been introduced and fieldwork? How does the academic content support the implementation of social work in the field? How has the creation of an ethical code and the establishment of a professional organization contributed to the development and improvement of the profession's standing? How does the instruction contribute to those practicing the professions? Finally, what do the narratives of the veteran workers imply about the chal- 
lenges facing the profession and its personnel?

\section{Definition of the social work profession}

Like other studies (Neipris, 1989; Shapiro et al., 1998), the interviewees in this study gave several different definitions of social work in the country. Some saw it as a kind of profession is not defined, there is a season, and a clear definition. Others argued that trade with the ideological essence designed to support and help to mediate and develop capabilities among the needy population. Some of the oldest social workers see the social work expresses a special action takes place only in one specific place and the social services department. A small portion of the respondents said this profession later became a special human being and educational in nature, and is becoming a thing of the special people with special characteristics.

\section{Reasons for choosing the social work profession}

This area has not been studied extensively. According to the existing literature, it seems that the need for skilled manpower has resulted in the establishment of professional training courses in the field of social work. Ministry of Welfare of the Government of Israel, who inherited the role of the social worker because he wanted to deal with the construction process and construction of the country, follow provide rapid response to citizens affected by the ravages of war and the masses of immigrants to Israel. Dealing in those situations demanded many compromises (Neipris, 1989).

The innovation that led to this study is that the vast majority of social workers claimed that the reasons oldest profession they choose, and other personal reasons, family, with personality, and the combination of three factors: personal, family and psycho Inter. In their view, these factors are helping people choose to study social work. Those interviewed stressed that other factors, like the satisfaction that makes the social worker profession, causing many to choose social work in their profession.

\section{Professional roles of the social work profession}

Mandate government believed the main role of social work is to maintain law and order, so rarely initiating welfare projects. However, when the establishment of the state social services have to deal with the consequences of war and mass immigration. Needs stemming from the very establishment of the state, such as mass immigration, necessitated the establishment of the state social service system to ensure immigrants with housing, employment, health and education (Shapiro et al., 1998).

Similar to that described in the literature, the vast majority of respondents described the transition from a profession is committed to helping alleviate underdevelopment profession aspires to become a professional treatment that provides emotional support, psychological and clinical care services. In their view, the main challenge in social work nowadays is to find ways to bridge the gap between those recipients, service providers, and reshape the relationships between them to ensure better service to vulnerable populations ink. This is the main condition for social work and innovation and the development of professional expertise.

\section{The roots of the social work profession}

The State of Israel has received from the government emerging social service system that served as a starting point for a welfare state. Social work done in this framework were the main characteristics of profession: paying jobs for professionals, vocational training facilities, professional organization's activities and professional publications (Shapiro et al., 1998). However, in recent years due to the injury status of the welfare state at the same time the increase in the number of voluntary organizations, social service providers, many changes have occurred in its identity, its missions and professional practice of social work, behavior and social workers in welfare (Freund, 2005).

Most participants argued that described in the literature, the roots of the profession in the country are religious, Jewish and Christian alike. One group of respondents believed over the years the concept of social work has changed and changed course of realization of ideas of compassion, partnership, commitment and equality, values that have made later to the principles and the basis of the new social work.

The novelty was raised by a small fraction of the interviewees who immigrated from the former Soviet Union. They said that more than one stream of social work in Israel. Our perception, social work has adapted to natives, and social work they have created themselves, appropriate to the characteristics of new immigrants arriving from Europe.

\section{Social work professional development causes in Israel}

With the establishment of the state, the social services had to deal with the consequences of war and mass immigration. They had to provide emergency assistance to those in need, ensuring immigrants with housing, employment, education and health services (Shapiro et al., 1998). Dealing with these situations required many 
compromises. The need of manpower led to the creation of short training courses and temporary reduction in the level of training (Neipris, 1989).

Most participants in the study showed a similar list of the key factors at stake in the development of social work in the country. In their view, these factors have changed always in the spirit of the period and in accordance with the changes that befell the society. Many social workers spoke about the increased number of inhabitants of the country, the change of government, participation in war, and change the type of social problems in quality and scope, as factors that influenced the development of this profession in the country. Another large part of the social workers at one point claimed oldest profession earned legitimacy and recognition among other groups and special population. The very resistance groups, at least initially, to use the services of social work in the country, there were groups in the kibbutz movement and the Arab and ultra-Orthodox populations.

\section{Professionalization of Social Work in Israel}

Even Israel's higher education system, and within training programs for social workers, underwent significant changes over the years. Academization of the profession began with the opening of the School of Social Work and Social Welfare in the name of Paul Berwald Hebrew University of Jerusalem. The decision then it was at the time of the determination of the basic training and practice in social work undergraduate studies will (Neipris, 1992).

Thus, as described in the literature, in the words of the interviewees were uploaded social work education in the country. The first training program of this profession lasted several months. Over the years, vocational training institutes were established and where it was possible to learn the profession until he received an academic status, then opened the first school to study social work in the country.

For many years, social work has included improving the process of professionalization of vocational training level, progress in research, diversity of practice areas, establishing trade union status, the rise of professional reputation, developing a code of ethics, and the enactment of laws that define the field of activity of the social worker and protect him. Increased sense of professionalism in the profession paying jobs right given to social workers, and thanks to the establishment of frameworks for practical training and professional enterprise activity.

Practice Areas Profession of Social Work in Israel

Social work in Israel was affected by the first of these approaches mainly European and American Southwest brought to Israel. Both approaches reflect the beginning of the targeting professionals, whether social reform in the settlement, and whether the focus on the individual and his family (Konrad, 1993; Neipris 1992).

According to veteran social workers, the impact of American models brought a focus on modern post method. Over the years, proved to access restrictions and social workers opened behavioral approaches, cognitive, ecological, critical and postmodern. Over time, the tendency was strengthened eclecticism.

Place Occupation of Social worker in Israel

At the beginning of social work, there were almost exclusively local offices of social work and only a few employees worked in other settings such as hospitals, test services, services for immigrants and schools. Over the years the system, a variety of activities, its distinctiveness, only 300 social workers, a third of the workers were local departments of social services (Shapiro et al., 1997).

One striking finding of the study related to the fact that today the social services departments of local authorities do not deal with the financial support and grants, except in emergencies. Today's social workers While inspecting their needs and rights of the customer, and engage in advocacy on it, are not inspecting their eligibility and administrative aspects of material assistance. So now they are more engaged in counseling, social care and development programs. Moreover, the social workers said that in recent years we have witnessed the establishment of new services such as family counseling stations, serving middle-class populations and not just needy. Apparent change largely led managers to promote the professionalization of social work.

\section{Potential Patients for Social Workers in Israel}

Could be impressed by the stories of those interviewed over the years to contact the social workers was a result of the reasons social, economic and others. A large part of the interviewees talked about the early days of the social work profession in the country, so people who wanted a social worker, they did so only to demand economic assistance and materials, and to obtain emotional support.

These findings meet the digits particular aspect of dedicated social work accent assistance to populations backward and needy, through interventions comprehensiveness regarding adaptation to the individual and to improve conditions for social through social action and social change at all levels, linking patients to resources exist and support social policy right to ensure the evenly split of resource (Han \& Chow, 2011). 


\section{Approaches to Treatment and Intervention Approaches in Social Work}

Another subject of the social workers came to the stories of veterans referred to the adoption of interventions in the treatment of overlapping. They stressed that there is no single theory in social work or some certain theories that can be used in overtime and in different contexts. One social worker was rather emphasized the specific job of the employee is the one that trained its employees to handle by a method prescribed by him. Here we note in front of the school of social work in Germany, came to Israel also has roots in social work Americans whose epicenter was individual treatment needs of the individual and his family (Prager, 1987).

Most participants believed that scientific research objectively and systematically important and necessary for their subject, but also as important as reflective thinking, that the professionals make a report with himself in his professional work and able to accept constructive criticism of its surroundings. The conclusion of the interviewees in social work in the country must generate knowledge that can be operated, so social workers can act on the ground so that they can contribute to changes in the lives of the populations are banished gaining access to appropriate services. Side and people distant from the eye rarely investigated, so intuitive social workers or workers who served them the tools users work with known populations more, or they create a search and creativity and invention interventions.

\section{Professional Status and Prestige of Social Worker in Israel}

Literature, just like the narratives of the interviewees in this study, is that the status of the profession, the social image of his self-image of its practitioners are influenced by several factors: legal status, degree of control over its areas of activity, the role of professionals in bureaucracies and composition in terms of their gender, level of education and income (Shapiro et al., 1998).

Veteran social workers also told a social worker now see a professional therapist advises individuals and families, requiring him to new marketing and other occupation. Revolution led to the creation of new services such as counseling, family, and also appeal to the middle class a few years ago that apparently was not treated by a social worker because he did not need allowances.

\section{Conclusion and Recommendations}

To date, studies in Israel and abroad addressed more professional development focused on describing the development profession as recorded by researchers and academics, rather than rely on the experiences and stories of the area, as was done in this study. This study came to fill this void in the literature, and it focuses on the personal experience of the veteran social workers and development professionals in this country. The developmental image of this profession in the country was affected by quantitative and qualitative research conducted in the field of academic and away from the field.

Therefore, the study results add to the understanding of professional settings, development and social challenges among older workers in the country. The new study indicates that the positive challenges of the profession, both in the eyes of veteran professionals are seeking to professionalize its eyes. It also indicates the importance of the study of the experience of practitioners and development professionals in the country perspective of those who founded and built the profession in the country. In addition, it provides other ways of thinking those who agonize over whether to specialize in this area.

The very focus of the suspect narrative recreates the story in clarifying the attitudes, feelings, memories and his beliefs, not just the researcher but also a number of stories. It is possible to identify moments when interviewed surprised themselves when they realized that they have a whole world of ideas and opinions regarding the profession, definitions, implications, vitality, nature and development. The very opportunity to talk about it and listening to gain control, it has a meaning for the respondents themselves and not something that serves only the research itself.

This study sheds light on the process leading to the professional identity of social workers, the factors that hinder and promote them on an individual level, local and national. Discussion in this process as part of the training of students and insights on this process may illuminate the way for young social workers and social work students in the country and raise their awareness of the electoral process in their personal and professional.

In addition, the study may help policy makers in the design and construction of future strategies. Learning experiences of senior social workers can also contribute in the construction of the curricula of schools of social work in the country and their fit with the changes that have occurred and still occur in areas of welfare in Israel.

Experience life and past experiences affect the design values and attitudes in the present. I think it is impor- 
tant to deepen this issue by making more comprehensive study to examine perceptions of social workers young and old, in various environments and varied cultural backgrounds. It is interesting, for example, to understand the perceptions of young social workers regarding the development of the profession today.

In summary, the findings highlight the differences in the veteran social workers' perceptions of the definition, nature, and role of social work in the country that parallel major developments of the profession in the country from its first days until the present, as reflected in the different periods of growth, expansion and development of the state of Israel. In the early days of the state, the profession was non-academic, and its main purpose was intervention and the provision of social services to weaker populations. Today it is a respected, academic profession with numerous areas of intervention and specialization that include both individual treatment and broad, extensive community intervention. The varied perceptions that individuals have toward the profession indicate that today a different attitude to the profession is called for, whether by those currently working in it or by those intending to engage in it in the future.

\section{References}

Bruner, J. S. (1986). Actual Minds, Possible Worlds. Cambridge, MA: Harvard University Press.

Freund, A. (2005). Work Attitudes of Social Workers across Three Sectors of Welfare Organizations: Public, For-Profit, and Third Sector. Journal of Social Service Research, 31, 69-92. http://dx.doi.org/10.1300/J079v31n03 04

Han, M., \& Chow, J. C. (2010). What Changes MSW Students' View on the Mission of Social Work? Social Work Education, 29, 205-221. http://dx.doi.org/10.1080/02615470902912227

Konrad, F. M. (1993). Wurzeln Juedischer Sozialarbeit in Palaestina. Weinheim: Juventa.

Neipris, J. (1989). Community Has Yet to State: Social Services and Social Work before the State. Information Social Workers, 5-12. (Hebrew)

Neipris, J. (1992). The American Joint Distribution Committee and Its Contribution to Social Work Education. Jerusalem: JDC.

Payne, M. (2005). Modern Social Work Theory (3rd ed.). London: Palgrave.

Prager, A. (1987). Western Impact on Education Lmktzoa-Time to Break Away from the Umbilical Cord. Social and Welfare, 2, 128-136.

Riessman, C. K., \& Quinney, L. (2005). Narrative in Social Work: A Critical Review. Qualitative Social Work, 4, $391-412$. http://dx.doi.org/10.1177/1473325005058643

Sarbin, T. R. (1986). The Narrative as a Root Metaphor for Psychology. In T. R. Sarbin (Ed.), Narrative Psychology (pp. 3-21). New York, NY: Praeger.

Shnit, D. (1998). The Law and Social Work Practice in Israel. In F. M. Loewenberg (Ed.), Meeting the Challenges of a Changing Society: Fifty Years of Social Work in Israel (pp. 51-74). Jerusalem: Magnes.

Shapiro, S., Scherer, M., \& Korin-lngr, N. (1992). Towards the Year 2000: Trends and Needs in Social Work. Tel Aviv University: School of Social Work Bob Safiel. (Hebrew)

Shapiro, S. E., Sherer, M., Korin-Langer, N., \& Weiss, I. (1997). Israel. In N. S. Mayades, T. D. Watts, \& D. Elliot (Eds.), International Handbook on Social Work Theory and Practice (pp. 223-244). Westport, CT: Greenwood Press.

Shapiro, S., Sherer, M., Korin-Langer, N., \& Weiss, I. (1998). The Professionalization of Israeli Social Work. In F. M. Loewenberg (Ed.), Meeting the Challenges of a Changing Society: Fifty Years of Social Work in Israel (pp. 29-50). Jerusalem: Magnes.

Shapiro, S., Scherer, M., Korin-lngr, N., \& Weiss, A. (2002). Development of Social Work Profession in Israel. Social and Welfare, 22, 135-152. (Hebrew) 


\section{Appendix}

\section{Interview Guide}

Personal and career development

- Motivation for choosing a profession.

- Learning Track.

- Factors that were influential figures on the selection.

- Development of career move.

- The degree of control in selecting the vocational track.

- Crises.

- Wish to change professional.

- Formative events that influenced the development of a professional career.

- Looking perspective on the selection-whether they would choose to re profession.

Perception and personal professional work of the interviewee

- Personal vision.

- Professional approach today, whether this perception changes have occurred over time.

- The content that will interest them during training today.

- Theoretical approaches offerings.

- Emphases professional approach: (as for example: adaptation/social change).

- The nature of the roles performed and promotions.

- Conflicts in various areas of activity.

- Dilemmas and professional dilemmas

Processes and changes affecting the profession in general

- Changes in emphasis.

- Changes in the population of Patients.

- Developments and interventions.

- Changes in the approach to patients.

- Exposure to international social work.

- The status of social workers past and present.

- Changes in social, political, policies affecting the profession.

- Changes in the organizations where they worked and employees.

- The role of social work in Israeli society in general.

- Allocation of resources profession effect on activity.

- The effect of the political and security situation.

\section{Experience of work}

- Experience success in realizing professional goals.

- General satisfaction and pleasure.

- Frustration and burnout.

- What like at work.

- What gives strength to stay in action.

- Experience personal growth.

- The relationship between personal life professional life.

- Remuneration paid.

Professional Ethics

- Contradictions between personal and professional values.

- Are any changes have occurred priorities in terms of professional ethics?

- Changes in legislation affecting the ethical issues.

Environmental reference on the profession

- Policy.

- Recipients.

- Other professionals.

- Other organizations.

Vocational training

- How training prepares professional life.

- Does vocational training was. 


\section{Academy-Field}

- Impact Academy on the work of the interviewee.

- Is there a mutual influence between the academic field.

Learning, training and workshops

- Learning opportunities career.

- Place the training (after graduate studies).

\section{Facing to the future}

- How to anticipate the future of social work.

- Changes that make future profession.

- The message to the future generation of social workers.

\section{Submit or recommend next manuscript to SCIRP and we will provide best service for you:}

Accepting pre-submission inquiries through Email, Facebook, LinkedIn, Twitter, etc. A wide selection of journals (inclusive of 9 subjects, more than 200 journals)

Providing 24-hour high-quality service

User-friendly online submission system

Fair and swift peer-review system

Efficient typesetting and proofreading procedure

Display of the result of downloads and visits, as well as the number of cited articles

Maximum dissemination of your research work

Submit your manuscript at: http://papersubmission.scirp.org/ 